\title{
CONSTRUÇÃO DO TRABALHO SOCIAL CRÍTICO NA COLÔMBIA
}

\section{Juan Pablo Sierra Tapiro}

Universidade Federal da Integração Latino-Americana (UNILA)

\section{A CONSTRUÇÃO DO TRABALHO SOCIAL CRÍTICO NA COLÔMBIA}

Resumo: Abordagem sobre a construção do Trabalho Social Crítico que surge e se consolida, na Colômbia, em um momento de acirramento da luta de classes nesse país. Para tal, faz breve referência ao caráter profundamente reacionário e antidemocrático do desenvolvimento capitalista-imperialista e a correspondente luta política e social pela construção de uma Colômbia com justiça social, democracia e soberania. Considerando tal particularidade histórica, reflete sobre o processo de consolidação do Trabalho Social Crítico na perspectiva de pensar alguns desafios políticos e teóricos, em sua articulação nacional e latino-americana, para continuar na disputa por um projeto ético-político profissional em face às classes trabalhadoras.

Palavras-chave: Luta de classes, trabalho social crítico, marxismo, América Latina, Colômbia.

THE CONSTRUCTION OF CRITICAL SOCIAL WORK IN COLOMBIA

Abstract: Approach on the process of constructing Critical Social Work in Colombia arises and consolidates itself at a time of fierce class struggle in the country. That's why we introduce this work with a brief reference to the deeply reactionary and undemocratic character of the imperialist-capitalist development and the corresponding political and social struggle for the construction of a Colombia with social justice, democracy and sovereignty. From this historic contextualization, it reflects about the process of consolidation of Critical Social Work to consider some political and theoretical challenges, in its national and Latin American articulation to keep for the dispute over a professional ethical-political project in regard to working classes.

Key words: Class struggle, critical social work, Marxism, Latin America, Colombia. 


\section{INTRODUÇÃO}

Caminante no hay camino,

Se hace camino al andar. (Antonio Machado).

Partimos do entendimento de que uma aproximação crítica marxista à realidade social colombiana, latino-americana e/ou mundial, implica aprendê-la como processo geral em movimento, na dialética da luta de classes, no capitalismoimperialismo vigente.

Mas, consequentemente com a perspectiva proposta, é necessário reconhecer as particularidades do desenvolvimento capitalista na região, onde prevalece um desenvolvimento desigual, combinado e dependente sob a hegemonia político-militar e econômica dos Estados Unidos da América (EUA). O que não implica homogeneidade nem ausência de resistências, lutas e tentativas de construir alternativas ou projetos de superação das relações de produção social capitalista.

$\mathrm{Na}$ particularidade da Colômbia, temos como produto da consolidação do desenvolvimento capitalista sob a hegemonia do capital transnacionalmonopolista, a conformação de um Estado oligárquico-burguês, cuja dominação tem se baseado na violência e nas práticas sistemáticas de terrorismo de Estado. Nesse sentido, o bloco dominante na Colômbia não se constituiu através de uma mudança das oligarquias crioulas dominantes para uma burguesia nacional, senão numa simbiose que reproduziu contraditoriamente interesses latifundiário-oligárquicos com tímidos interesses de desenvolvimento capitalista próprios de burguesias historicamente servis à principal potência capitalistaimperialista (EUA); interesses que hoje confluem plenamente entre si (com poucas exceções de alguns setores industriais médios).

O que tem levado a não realização dos mínimos necessários para reformas políticas, sociais e econômicas, próprios de uma sociedade burguesa. Ao contrário, com o desenvolvimento da economia ilegal do narcotráfico, ligada aos processos legais (e não por isso legítimos) de financeirização da economia, o que se têm produzido nas últimas décadas são a expansão e aprofundamento do autoritarismo e do uso da violência estatal (incluída a estratégia paramilitar) para garantir as condições da sua reprodução.

Mas por outro lado, também encontramos uma classe trabalhadora profundamente combativa e diversa, que é não pode ser reduzida aos termos do típico operariado industrial, o que coloca tons diferentes na organização e nas respostas das lutas das classes trabalhadoras, urbanas e rurais. Com um protagonismo ainda vigente dos camponeses na resistência à dominação e violência oligárquicoburguesa, onde um importante setor encontrou na luta armada sua única via de sobrevivência e possibilidade de luta pelas reformas políticas, sociais e econômicas necessárias ou, inclusive, na construção de uma alternativa de superação da sociedade burguesa numa perspectiva revolucionária.

$\mathrm{Na}$ América Latina em geral as reformas democrático-burguesas não foram, nem serão, plenamente feitas pelas burguesias nacionais, já que o próprio desenvolvimento capitalista está subordinado às potencias imperialistas.

No caso da Colômbia isso é ainda mais grave dada a falta de condições mínimas para a realização da disputa pelo poder político, inclusive na limitada democracia burguesa, com sistemáticas e reiteradas experiências de perseguição e extermínio dos processos democráticos de esquerda e de oposição (não exclusivamente marxistas, socialistas ou comunistas) à hegemonia vigente; com uma grande concentração da terra, aprofundada com permanentes processos de despojo via deslocamentos forçados armados pelas forças legais ou ilegais do Estado e ligadas às classes dominantes e aos interesses transnacionais monopolistas; e consequentemente sob condições do maior servilismo às potencias imperialistas, especialmente aos EUA.

Por isso, a luta pela paz na Colômbia, onde atualmente conflui uma ampla diversidade das organizações e movimentos das classes trabalhadoras historicamente expropriadas e exploradas, assim como de diversos setores sociais que têm sofrido com as práticas de opressão do terrorismo de Estado, tem como bandeira principal que essa paz deve ser com justiça social, democracia e soberania.

O que implica em uma reforma agrária e urbana com o uso da terra respeitando a diversidade cultural e colocando no centro a soberania alimentar; garantias para a luta política sem armas e sem ingerência nos assuntos internos por parte dos EUA; reformas soberanas que possibilitem a efetivação de direitos sociais por via de políticas sociais; além, claro, de um processo de verdade histórica, reparação das vítimas e garantias de não repetição.

O Trabalho Social ${ }^{2}$ na Colômbia, historicamente, tem dado as costas à realidade da guerra como uma forma de expressão da luta de classes, consolidando uma hegemonia de pensamento/atuação na qual confluem diversas perspectivas com traços de endogenismo e seu consequente epistemologismo ${ }^{3}$. Isto ficou ainda mais evidente no silêncio ou na tímida analise crítica durante os anos de terror dos governos de Uribe Vélez (2002-2006 e 2006-2010), na consolidação de um projeto reacionário de ultra-direita e na materialização mais profunda da estratégia neoliberal do capitalismo-imperialismo nas últimas décadas e seus rebatimentos nas políticas sociais, e na continuidade com matizes e contradições do 
atual governo de Santos Calderón (2010-2014 e 2014-2018).

Nesse contexto, surge e se consolida o processo de Trabalho Social Crítico da Colômbia, como experiência organizativa profissionalestudantil, que se coloca em contradição com o Trabalho Social conservador que historicamente tem sido hegemônico. O Trabalho Social Crítico se propõe a recuperar a herança teórico-metodológica de Marx, para as análises críticas da sociedade e para fundamentar a construção de um projeto éticopolítico profissional, assim como na articulação com outros processos em uma perspectiva de se assumir profissionalmente na luta de classes.

Após 12 anos do surgimento do Coletivo Trabalho Social Crítico, faremos uma breve apresentação do seu processo. Tendo como base de análise o processo do movimento atual da realidade social colombiana, com destaque do processo de paz, assim como a conjuntura na região, propomos alguns desafios para esse Coletivo, na sua articulação nacional e latino-americana.

\section{SURGIMENTO E CONSOLIDAÇÃO DO TRABALHO SOCIALCRÍTICO DACOLÔMBIA ${ }^{4}$}

Em um contexto nacional marcado pela intensificação do terrorismo de Estado sob o primeiro Governo de Uribe Veléz; ; mas por sua vez, contraditoriamente, marcado pelos ares de uma virada (diversa e diferenciada) à esquerda no continente (com governos progressistas que diante das nefastas consequências do neoliberalismo se constituíam - alguns mais em aparência que em essência - em alternativas de soberania, autodeterminação e anti-neoliberalismo), o processo de Trabalho Social Crítico da Colômbia surge como uma expressão da luta de classes; na batalha das idéias de uma categoria profissional, pretendendo a superação de um Trabalho Social tradicional e conservador de costas à realidade social colombiana.

Diante do fracasso das tentativas de uma organização colombiana de estudantes de Trabalho Social ${ }^{6}$, recém-formados e estudantes da Universidade Nacional da Colômbia (Unal) decidem, em 2004, conformar um grupo de estudo: Trabalho Social Crítico, e a partir desse processo organizam em 2005 o I Encontro Latino-americano de Trabalho Social Crítico, no qual convidam acadêmicos de peso do debate profissional na região continental ${ }^{7}$, com o intuito de ter uma visão panorâmica das diversas tendências teórico-políticas que se assumiam como críticas, em uma perspectiva de transformação social, assim como para tentar identificar alguns pontos mínimos comuns que permitissem a continuidade de um processo de articulação continental.

Nesse sentido, propõe-se uma reflexão crítica entorno à formação, pesquisa e ação profissional, baseada num posicionamento ético e político que superasse o pressuposto da neutralidade profissional e que entendendo a função reprodutora do Trabalho Social na divisão social do trabalho, se posicionasse na perspectiva dos interesses das classes trabalhadoras.

O grupo da Unal reafirma sua opção por assumir o materialismo dialético como perspectiva teórico-metodológica e política para seu processo de auto-formação e consequentemente o socialismo como projeto societário ao que se pretenderia contribuir. Para isso, a principal referência no debate profissional seria o acúmulo na construção de um projeto ético-político no Brasil.

A partir desse momento começa um processo de tentativa de articular iniciativas de grupos de Trabalho Social Crítico em outras universidades, o que faz com que o perfil que se afirma é principalmente o estudantil. Assim, conformamse grupos ou coletivos em Bucaramanga, na Universidade Industrial de Santander (UIS) (2006), em Cali, na Universidade del Valle (Univalle) (2007) e em Manizales, na Universidade de Caldas (Caldas) (2007) (COLETIVO TRABALHO SOCIAL CRÍTICO DA COLÔMBIA, [20--?]).

Porém, cada processo teve suas particularidades. Enquanto na UIS as propostas da Unal foram plenamente assumidas, na Univalle e em Caldas o debate foi em torno de como se entendia $o$ crítico, não assumindo a priori o acúmulo do debate e do processo da Unal; e problematizando o fato de que a única vertente crítica fosse fundamentada no marxismo e que o projeto societário objetivado fosse o socialismo.

Essas diferenças se fundavam basicamente em três elementos:

1) Uma idéia autonomista da Univalle e de Caldas, que percebiam uma postura vertical por parte da Unal. Univalle e Caldas queriam ser parte de uma articulação nacional de Trabalho Social Crítico sem perder a sua autonomia e sem ter uma apropriação dos acúmulos de três anos da Unal. Esta, por sua vez, queria conseguir aglutinar os segmentos estudantis que se assumiam como críticos, colocando como ponto de partida o seu acúmulo;

2) Uma pluralidade na composição interna dos coletivos da Univalle e de Caldas, de diferentes experiências e afinidades teóricas e políticas (além da evidente insuficiência e muito superficial formação em uma perspectiva marxista), que em um contexto de aprofundamento da guerra e do terrorismo de Estado (já no segundo Governo de Uribe Vélez), implicava em mais prevenções ainda para assumir os pressupostos colocados como pilares do processo por parte da Unal e assumidos também pela UIS;

3) Em consequência dos dois elementos anteriores foi crescendo uma certa desconfiança, assim 
como uma discussão em torno da possibilidade da unidade na diferença e da necessidade de se construir um acúmulo coletivo em nível nacional por parte de todos os coletivos (COLETIVO TRABALHO SOCIAL CRÍTICO DA COLÔMBIA, [20--?]).

Como resultado, foi possível avançar na articulação dos processos em nível nacional, mas houve um retrocesso em termos do acúmulo teóricopolítico que já havia sido conseguido pela Unal, o que implicou necessariamente uma retomada de debates que eles consideravam superados. Mas, como veremos, isso terminou fortalecendo o processo como um todo, no sentido que se construiu um acúmulo coletivo no qual se assumiu efetivamente a perspectiva já proposta pela Unal.

Em 2007, o grupo da Unal (já nesse momento com mais graduados do que estudantes) e o grupo da UIS, iniciaram a organização do I Congresso Latino-americano de Trabalho Social $\mathrm{Crítico}^{8}$, no qual se pretendia, diferentemente do I Encontro, um aprofundamento no debate profissional a partir de uma crítica marxista. Porém, por diversos motivos, não foi exatamente isto que aconteceu.

Inicialmente, pretendeu-se a participação internacional de um convidado do Brasil e um da Argentina $^{9}$, que assumissem como perspectiva teórico-política o marxismo, mas no final os convidados foram os argentinos Marcelo Cortizzo (na época diretor da Escola de Trabalho Social da Universidade das Mães da Praça de Maio) e Norberto Alayón (destacado acadêmico e referência do debate profissional na região continental desde o processo de Reconceitualização). O primeiro efetivamente fez uma apresentação a partir do marxismo, enquanto o segundo tem historicamente tido uma perspectiva de diálogo com o marxismo, mas com claras diferenças e tensões teóricas, metodológicas e políticas.

Além disso, vários dos trabalhos que foram apresentados, mesmo que se colocavam desde uma perspectiva crítica com respeito ao Trabalho Social tradicional e conservador na Colômbia, assumiam um diálogo com o marxismo, mas fazendo destaque à necessidade de articulação com os pensamentos de Paulo Freire ou de Foucault, em uma apreensão mais eclética que profunda sobre as possíveis pontes e as distâncias dessas perspectivas.

Portanto, o I Congresso não conseguiu o objetivo de aprofundar a partir de uma análise exclusivamente marxista a apreensão da realidade social colombiana e latino-americana em face aos processos de dolarização do social ${ }^{10}$, das consequências da estratégia neoliberal vigente e das possibilidades e estratégias de resistência e luta social e profissional.

Mas, por outro lado, o evento conseguiu novamente uma importante participação estudantil, e o processo ganhou visibilidade enquanto alternativa organizativa, como uma proposta de crítica ao Trabalho Social tradicional e conservador.

Após o I congresso em 2008, em Bogotá, conforma-se sob tutela do grupo da Unal um novo grupo na Universidade Republicana (primeiro coletivo conformado em uma universidade privada). Também, em 2008, começam as primeiras aproximações e tentativas de conformação de coletivos em Armenia, na Universidade de Quindío, e em Medellín, na Universidade de Antioquia, os quais se conformaram efetivamente em 2009 (COLETIVO TRABALHO SOCIAL CRÍTICO DA COLÔMBIA, [20$-?])$.

No primeiro semestre de 2009, pretendiase começar a organização do II Congresso Latinoamericano para esse ano, mas as divergências entre os coletivos, que cada vez se intensificavam mais com respeito a assumir, ou não, a perspectiva crítica exclusivamente marxista, assim como o vazio que a maioria dos coletivos conformados entre 2007 e 2009 sentiam com relação à construção de um projeto ético-político, levaram ao adiamento da organização desse congresso, e da priorização de um I Encontro e Assembleia de Trabalho Social Crítico da Colômbia (COLETIVO TRABALHO SOCIAL CRÍTICO DA COLÔMBIA, [20--?]).

A partir desse I Encontro e Assembleia, onde foi realizada uma discussão teórico-política sobre marxismo, socialismo e projeto ético-político profissional, foram construídos os princípios do processo em nível nacional. Estes seriam entendidos como os pontos mínimos comuns, a partir dos quais cada coletivo manteria sua autonomia e que igualmente deveriam ser assumidos por novos possíveis coletivos, para evitar um retrocesso dos acúmulos teórico-políticos do processo como um todo, como havia acontecido no passado.

Esses princípios têm sido revisados de forma permanente nas assembleias, mantendo-se em essência, mas com alguns ajustes. Também foram realizados alguns fóruns de debate e a fundamentação dos mesmos tem sido construída coletivamente; embora ainda falte um debate com maior aprofundamento sobre o que esses princípios implicam em termos práticos, para pensar sua materialização e desdobramentos; sobre o que se começa a se avançar recentemente.

Esses princípios, discutidos e atualizados na VI assembleia, de setembro de 2015, são:

- Impulsionar a construção de um projeto éticopolítico profissional para a renovação crítica do Trabalho Social na Colômbia.

- Apropriar os fundamentos teóricometodológicos do materialismo dialético e histórico, contribuindo com as análises concretas e a transformação da realidade social.

- Assumir-nos como parte da classe trabalhadora 
e participar de processos de lutas sociais e de classes.

- Articular-nos internacionalmente com processos profissionais a partir de uma perspectiva latinoamericanista.

Em termos organizativos, em 2009, ficou decidido manter uma coordenação dos coletivos regionais e se assumir como processo articulado nacionalmente. Nesse ano foram suspendidos os trabalhos em Armenia e Bucaramanga, os quais se têm tentado reativar em diversos momentos sem sucesso ${ }^{11}$.

Retomou-se a organização do // Congresso Latino-americano de Trabalho Social Crítico, realizado em 2010, novamente com a intenção de aprofundar em uma perspectiva marxista de análise e debate sobre o tema da construção de projetos ético-políticos profissionais. Contou-se com a participação internacional, como convidados, de Alejandro Casas (Uruguai), Carlos Montaño (Brasil), e Lorena Molina (Costa Rica). Montaño e Molina claramente assumem uma perspectiva marxista, já Casas dialoga com essa perspectiva, mas faz uma ênfase na necessidade de recuperar o pensamento latino-americano e pensar a partir da descolonização do saber, valorizando também processos autônomos de luta no continente, não necessariamente baseados numa perspectiva marxista.

$\mathrm{Na}$ maioria dos trabalhos apresentados também se retomou uma aproximação com as perspectivas marxistas de análise. Definitivamente foi um congresso que logrou uma maior consistência em termos teóricos e políticos. Assim como logrou a participação de estudantes e profissionais de outros países como Argentina, Brasil e Equador.

Nesse ano foi decidido que a referência dos coletivos não seria mais as universidades e sim os municípios, isto por ter a possibilidade de haver diversos processos em um mesmo município (Bogotá, por exemplo, começou a ter coletivos em diversas universidades privadas) e porque cada vez haviam e teriam mais membros recém-formados, alguns que atuariam como profissionais, outras/ os como docentes e outras/os que continuariam seus estudos de pós-graduação no país ou no exterior (especialmente no Brasil; o que por um lado fortaleceria o debate teórico-político do Coletivo, mas que, por outro lado implicava em processos de renovação geracional, que em geral não se conseguiu planejar da melhor maneira para afetar o menos possível as dinâmicas locais.

Em 2012 foi conformado o Coletivo de Rio de Janeiro, com militantes que vinham do processo na Colômbia e que estão fazendo estudos de pósgraduação nessa cidade, o que tem fortalecido a projeção internacional do processo ${ }^{12}$. Também se tentou a conformação de um coletivo em Buenos Aires e La Plata Argentina, mas sem sucesso

\section{(COLETIVO TRABALHO SOCIAL CRÍTICO DA COLÔMBIA, [20--?]).}

De 2009 a 2015 houve um importante fortalecimento e amadurecimento das reflexões coletivas, destacadamente nos coletivos locais nos seus processos de auto-formação, com diversas atividades de fóruns, com participação em eventos locais, nacionais e internacionais, com produções acadêmicas que começaram a mobilizar debates a partir da proposta do Trabalho Social Crítico da Colômbia, entre outros.

Mas, além disso, uma característica que cada vez tem se intensificado é de que os membros do Coletivo na sua maioria participam ou são militantes em outros processos organizativos como movimentos sociais, movimentos e/ou partidos políticos, entre outros, não se limitando ao movimento estudantil universitário e nem da categoria profissional; o que por sua vez também tem influenciado em uma maior qualificação do Coletivo, que na pluralidade tem conseguido manter sua unidade com base nos princípios acordados assumidos como pontos mínimos comuns.

Esse fortalecimento e mudança de perfil claramente correspondem ao auge da luta social na Colômbia, com um importante triunfo do movimento estudantil universitário em 2011 ao barrar uma reforma da Lei de Educação Superior que pretendia aprofundar o seu fundamento neoliberal; e sobretudo, com o fortalecimento e consolidação de movimentos como a Marcha Patriótica, o Congresso dos Povos, entre outras plataformas de unidade social e política, que têm mobilizado uma agenda de luta pela paz com justiça social, pelos direitos humanos, pela reforma agrária, pela soberania e a democracia; e especialmente a partir da abertura do diálogo de paz entre o Governo de Santos Calderón e das Forças Armadas Revolucionárias da Colômbia - Exército do Povo (FARC-EP) desde 2012. Isto tem possibilitado outro cenário para a organização e mobilização social, diferente ao estado de terror e de práticas ditatoriais do Governo de Uribe Vélez (com Santos Calderón no seu segundo período como Ministro de Defesa), ao reconhecer a existência do denominado conflito armado e, portanto, reconhecer as guerrilhas como atores políticos em armas; mesmo que as práticas de perseguição e repressão ainda se mantêm.

Entre 2012 e 2014 foi organizado o Terceiro Congresso Latino-americano de Trabalho Social Crítico, comemorativo dos dez anos do processo de Trabalho Social Crítico da Colômbia. Nesse evento se debateu sobre as lutas sociais no contexto latinoamericano onde a ofensiva neoliberal mantém vigência, com matizes e processos de resistência permanentes, num momento em que fica mais evidente os limites da maioria de processos da denominada virada à esquerda da década anterior e das contradições em seu interior para consolidar um 
bloco anti-neoliberal e anti-imperialista ${ }^{13}$.

Os convidados internacionais e nacionais ${ }^{14}$, assim como a maioria de trabalhos apresentados ${ }^{15}$, assumiam-se enquanto uma perspectiva marxista, com matizes entre si, o que também já permitiu começar de maneira mais clara a evidenciar a heterogeneidade no marxismo e na apreensão da realidade latino-americana, das lutas sociais e de classes e das possibilidades e limites profissionais de contribuição nessas lutas.

Desta vez, propositalmente foram aceitos trabalhos que se propondo como críticos não se assumiam a partir de uma perspectiva marxista, ainda que dialogassem com esta. Assim, foram apresentados trabalhos que incorporavam elementos de perspectivas do paradigma da complexidade, do pós-estruturalismo, do pós-modernismo, entre outras.

Isto possibilitou assumir um debate importante entre perspectivas diversas, no qual ficou clara a diferenciação entre a produção do Coletivo (fundamentada no marxismo) e outras perspectivas (marcadamente ecléticas), o que é muito necessário para tentar construir na diferença, e para somar com todas as forças que no debate profissional se pretendem críticas ao Trabalho Social tradicional e conservador, mais ainda tendo em conta os limites da produção teórica na Colômbia.

Mas, por sua vez, a participação desses trabalhos pode ter provocado confusões no público em geral (que na sua maioria eram estudantes), o que na avaliação de alguns companheiros/as ou coletivos sua aprovação teria sido um erro.

Por fim, analisando o processo descrito de surgimento e consolidação do Trabalho Social Crítico da Colômbia, poderíamos sintetizá-lo da seguinte maneira: 2004-2005 - Surgimento; 20052007 - Primeiro processo de consolidação; 20072009 - Contradições e fraturas; 2009-2015 - Segundo processo de consolidação.

Entendendo o momento atual como parte do processo de consolidação (o que não implica falta de dificuldades e contradições), é necessário pensar e agir sobre os diversos desafios que o Coletivo tem para enfrentar, que têm surgido ao longo desses 12 anos. Tanto para uma consolidação maior do processo na Colômbia, mas também na articulação com outros processos irmãos na América Latina. Não pretendemos aqui esgotá-los, mas sim indicar os que consideramos mais urgentes para continuar dita consolidação ${ }^{16}$.

\section{DESAFIOS DO TRABALHO SOCIAL CRÍTICO DA COLÔMBIA.}

A Colômbia atualmente está em um processo de paz que implica não somente no diálogo com as insurgências armadas das FARCEP, Exército de Libertação Nacional (ELN) e Exército
Popular de Libertação (EPL) ${ }^{17}$, mas também na participação efetiva do conjunto das organizações e dos movimentos sociais e políticos, dos sujeitos historicamente expropriados, explorados, perseguidos e exterminados ${ }^{18}$.

A construção e consolidação de um Trabalho Social Crítico na atual conjuntura da Colômbia coloca a ênfase na luta pela paz com justiça social, democracia e soberania; na construção da memória histórica para a garantia de não repetição; e no fortalecimento da organização e mobilização social no acirramento das lutas de classes e nas disputas de projetos de país. São sobre essas bases que precisamos pensar os nossos desafios.

Entendemos os desafios do Trabalho Social Crítico da Colômbia na necessidade de tratar e mobilizar debates teórico-políticos e práticos no interior do Coletivo e também fora deste. Entre alguns dos temas que historicamente têm surgido temos:

Teoria(s) crítica(s) - Esse é um debate que tem surgido em diversos momentos do processo. É necessário aprofundar a reflexão das teorias que se colocam como críticas, analisar criticamente as mesmas, destacando os elementos que possam ser resgatados e apontando seus limites e contradições. Sobretudo demonstrando a pertinência e a necessidade da apreensão teórico-metodológica e política que se encontra na herança de Marx, na crítica da Economia Política, no método materialistadialético e numa perspectiva revolucionária da classe trabalhadora, para as análises das realidades concretas e nas perspectivas de ação profissional.

Marxismo(s) - Assumir o marxismo não pode ser apenas uma palavra de ordem. É necessário o estudo para sua apreensão e nesse caminho é importante identificar e entender as diferentes correntes da tradição marxista, assim como realizar análises concretas da nossa realidade social e da profissão.

Lutas de classes, guerra e imperialismo na Colômbia - Assumindo a herança teóricometodológica e política do Marx e Engels, é preciso analisar em termos concretos os processos das lutas de classes na Colômbia, suas particularidades a partir da guerra, consequência da estratégia imperialista-militarista de um desenvolvimento capitalista baseado na violência aberta (oficial e paramilitar), na opressão e repressão das vozes dissidentes, opositoras, subversivas e seu extermínio físico. Está também aqui a chave para contribuir no processo de paz, através de análises teóricas, mas também a partir da ação profissional fundamentada na apreensão do movimento da realidade social.

Projetos políticos anticapitalistas - No interior do Coletivo está clara e assumida uma perspectiva anticapitalista. Apesar de que desde 2011 o socialismo tenha sido assumido como projeto societário, isto não foi feito público em 
documentos e nem nos princípios. Por isso, é necessário um debate que possibilite amadurecer o tema coletivamente, inclusive porque em vários momentos surgem novamente inquietações com respeito a outros possíveis projetos anticapitalistas diferentes ao socialismo. E, mais ainda, para pensar projetos de país em um novo cenário de paz, o que possibilitaria aprofundar a reflexão coletiva sobre o projeto profissional.

Perspectivas no Trabalho Social na Colômbia e América Latina - A proposta do Trabalho Social Crítico precisa uma apreensão das tendências que se apresentam no país e na região continental, passando pelas propostas de renovação conservadora (em toda sua diversidade), até as propostas que se colocam como alternativas e/ou críticas. Assim como identificar os processos que se constroem também em uma perspectiva de renovação profissional crítica baseada no marxismo como fundamento. Esta apreensão é chave para a construção de um projeto ético-político profissional, para entender as possibilidades e limites, baseados nas confluências e diferenças entre diversas perspectivas profissionais. Isto também é importante para analisar a história escrita da profissão e propor novas análises interpretativas do surgimento, desenvolvimento e atualidade do Trabalho Social na Colômbia e América Latina (COLETIVO TRABALHO SOCIAL CRÍTICO DA COLÔMBIA, [20--?]).

Mas, para conseguir o trato e a mobilização desses debates é claro que o Coletivo precisa fortalecer seus processos de auto-formação locais e nacional. Evidentemente, é importante o diálogo com outros profissionais que estejam fora do Coletivo e da categoria, mas que compartilhem as inquietações e propostas e/ou que tenham um acúmulo ao respeito.

Outro desafio tem a ver com o necessário fortalecimento organizativo do Trabalho Social Crítico da Colômbia, construindo uma proposta estratégica que possibilite realmente projetar a disputa da hegemonia de um novo projeto profissional. Esse fortalecimento também passa pela possibilidade de permanência no processo dos profissionais e docentes, assim como a chegada de novos estudantes e profissionais.

Nesse sentido é importante lograr cada vez uma maior presença nos debates da categoria. Ao respeito, recentemente em assembleia, concluiuse sobre a necessidade e pertinência da atuação como Coletivo nos diversos espaços institucionais, a partir dos processos locais de representação ou organização estudantil, da participação nos Encontros Nacionais de Estudantes de Trabalho Social, nos Congressos Colombianos de Trabalho Social, e inclusive nas entidades da categoria como Conselho Nacional para a Educação em Trabalho Social (CONETS), na Federação Colombiana de Trabalhadores Sociais (FECTS) e nas respectivas associações regionais, e no Conselho Nacional de
Trabalho Social.

Nesse sentido o Coletivo pretende começar a trilhar um caminho para afetar de maneira efetiva a institucionalidade, assumindo sua vocação de renovação profissional. Para isso é necessário o fortalecimento organizativo, não só do Coletivo, mas da categoria (estudantes, profissionais e docentes). Além da articulação com aqueles que, mesmo fora do Coletivo, estejam próximos teórica e politicamente, e que possam ser aliados na construção do projeto ético-político profissional e na disputa pela hegemonia ${ }^{19}$.

Também é importante pensar a possibilidade de recuperar duas propostas que não são excludentes, mas que efetivamente devem ser diferenciadas. A realização de encontros entre perspectivas que se coloquem como críticas, ainda que não se assumam exclusivamente marxistas; e a realização de encontros onde confluam não apenas profissionais do Trabalho Social, mas que assumam sim essa perspectiva teórico-metodológica e política.

Nesse sentido está em processo de reflexão o caráter dos congressos latino-americanos de Trabalho Social Crítico, assumindo uma convocatória aberta, mas com clara direção a partir do marxismo, tentando apontar para intercâmbios e reflexões coletivas e para a construção de propostas concretas de articulação da profissão na região continental.

Desta maneira é importante definir uma estratégia de atuação internacional que possibilite consolidar a articulação e aprendizagem com outros processos irmãos na América Latina que estão, com acúmulos diferenciados, na mesma aposta de construção. Para isso, os intercâmbios em todos os eventos onde forem possíveis (próprios ou não), o fortalecimento da comunicação nas redes virtuais, e a pesquisa e produção acadêmica própria (sobretudo coletiva) e sua difusão, são fundamentais.

Finalmente, o Coletivo tem como desafio a análise dos processos organizativos sociais e políticos em luta, com os quais considere que pode ter articulação (e nos quais inclusive já têm militâncias compartilhadas). E, assim, contribuir dentro de suas possibilidades e limites com as lutas sociais e de classes no país; especialmente neste momento de construção de uma grande frente na luta pela paz com justiça social, democracia e soberania, momento tático fundamental na possibilidade da luta pela construção do socialismo.

\section{CONCLUSÃO}

As possibilidades e limites de uma renovação crítica da profissão está determinada em boa parte pelos processos sociais e particularmente pela luta de classes. Atualmente a conjuntura latino-americana está cada vez mais complicada em termos de uma retomada importante da direita reacionária e da estratégia neoliberal no continente 
em diversos países e por diversas vias.

A Colômbia, mais uma vez, pode estar na contramão das tendências regionais, com um grande acúmulo e potencial de luta; se conseguir materializar a abertura de um processo de democratização política e social, possibilitando a disputa de projetos de país sem que a ameaça, o deslocamento forçado, o exílio, o cárcere e a morte sejam uma constante da prática política do bloco oligárquico-burguês, ainda no poder. A Colômbia potencialmente poderá ser um farol de esperança e de suporte para os processos de resistência e transformação social na América Latina, já que a mobilização e luta social nesse país se intensificaria ainda mais.

Não obstante, essa nova conjuntura dificulta essa materialização, já que se fortalece uma estratégia de retomada intervencionista político-militar e econômica dos EUA, onde o papel geopolítico da Colômbia é fundamental, e a estratégia paramilitar-contrainsurgente é exportada aos outros países da região.

É por isso que é preciso fortalecer os vínculos entre os processos e organizações das classes trabalhadoras. Temos também a nossa responsabilidade aí, desde a necessária articulação dos diversos processos que assumimos na luta pela renovação profissional, na batalha das idéias e na disputa da orientação hegemônica do Trabalho Social, em face aos processos de resistência e transformação na Nossa América.

\begin{abstract}
En una fonda de Madrid haun letrero que dice: prohibido cantar

En el aeropuerto de Rio de Janeiro hay un letrero que dice: prohibido jugar con los carritos porta-valijas [...]

En Colombia todos los días escriben en los cuerpos de campesinos, estudiantes, indígenas, trabajadores, mujeres, niños: prohibido pensar, prohibido luchar, prohibido protestar.

Esto quiere decir: todavía hay gente que canta, todavía hay gente que juega [...] Y en Colombia, como en el resto de América Latina, así les moleste a algunos y algunas, todavía hay gente que piensa lucha y protesta! (Adaptación de Ventana de las prohibiciones de Eduardo Galeano).
\end{abstract}

\section{REFERÊNCIAS}

COLETIVO TRABALHO SOCIAL CRÍTICO DA COLÔMBIA. [Atas das Assembleias e outros documentos internos]. [S. I: s. n.], [20--?].

COMISSÃO HISTÓRICA DO CONFLITO E SUAS VÍTIMAS. Contribución al entendimiento del conflicto armado en Colombia. Bogotá, 2015. Disponívelem:<https://www.mesadeconversaciones. com.co/sites/default/files/Informe\%20Comisi_n\%20 Hist_rica $\% 20$ del $\% 20$ Conflicto $\% 20 y \% 20$ sus $\% 20$ _ ctimas. \%20La\%20Habana \%2C\%20Febrero $\% 20$ de\%202015.pdf>. Acesso em: 1 jan. 2016.

CONTRERAS, A. América Latina en la geopolítica del imperialismo. In: CONGRESSO LATINOAMERICANO DE TRABALHO SOCIAL CRÍTICO, 3., 2014, Cali. Anais... Cali, 2014.

DUARTE, D. R. Las luchas de resistencia y los gobiernos de izquierda en América Latina: el papel de Colombia en el periodo 2002-2010. In: CONGRESSO LATINO-AMERICANO DE TRABALHO SOCIAL CRÍTICO, 3., 2014, Cali. Anais... Cali, 2014.

LONDOÑO, S. A. Q. (2014). Breves notas sobre el impacto del neoliberalismo en la luchas de clases. In: CONGRESSO LATINO-AMERICANO DE TRABALHO SOCIAL CRÍTICO, 3., 2014, Cali. Anais... Cali, 2014.

ROMERO, A. T.; NEISA, R. P. La organización profesional como clase asalariada y la construcción de un proyecto ético-político profesional crítico: una propuesta desde el trabajo social para la articulación con las fuerzas sociales de las clases subalternas en la lucha de clases en Colombia. In: CONGRESSO LATINO-AMERICANO DE TRABALHO SOCIAL CRÍTICO, 3., 2014, Cali. Anais... Cali, 2014.

SALAMANCA, R. Trabajo Social Crítico: la perspectiva profesional en el contexto Latinoamericano. 2010. Dissertação (Mestrado em Serviço Social) - Universidade Federal do Rio de Janeiro, Rio de Janeiro, 2010.

TAPIRO, J. P. S. A vigência da luta de classes e a construção de um Serviço Social crítico na América Latina. Praia Vermelha, Rio de Janeiro, v. 24, n. 2, 2015.

Posibilidades de un Trabajo Social Crítico en Colombia. Revista Prospectiva, Cali, n. 18, p. 69-99, 2013.

Trabajo Social en Colombia: una propuesta de renovación desde una crítica marxista. 2012. Dissertação (Mestrado em Serviço Social) - Universidade Federal do Rio de Janeiro, Rio de Janeiro, 2012.

\section{NOTAS}

1 A base desse artigo foi o trabalho apresentado na mesa temática: Perspectivas do pensamento crítico no Serviço Social na América Latina, na VII Jornada Internacional de Políticas Públicas (JOINPP) na Universidade Federal de Maranhão, realizada em agosto de 2015 . 
2 Para este trabalho optamos pela expressão Trabalho Social, que seria a tradução textual, retomando a forma como é nomeada a profissão em geral, e não Serviço Social, como é chamada particularmente no Brasil, em virtude de seus debates profissionais.

$3 \mathrm{Na}$ dissertação de mestrado O Serviço Social na Colômbia: uma proposta de renovação desde uma crítica marxista defendida em fevereiro de 2012, encontramos elementos de análise que possibilitam sustentar essa hipótese, embora seja necessário um maior aprofundamento da mesma. Em Tapiro (2013) achamos uma síntese dessa hipótese.

4 A continuação faremos uma breve apresentação desse processo, destacando alguns elementos que consideramos chaves para entendê-lo, mas sem nenhuma pretensão de esgotar a recuperação histórica do mesmo e uma análise coletiva e sistemática que está começando no Coletivo. Esta localização será a base para pensar os desafios do Trabalho Social Crítico da Colômbia.

5 Uribe Veléz chegou ao governo em 2002, após o fracasso do diálogo de paz entre o governo de Andrés Pastrana e as FARC-EP prometendo vencer e acabar com as guerrilhas pela via militar (principalmente as FARC-EP, mas também o ELN e o EPL). Sua proposta era dar continuidade e aprofundar o chamado Plano Colômbia, que foi implementado pelo governo Pastrana paralelamente ao diálogo de paz. Nesse plano, ideado, orientado e financiado pelos EUA na suposta luta contra o narcotráfico e, posteriormente, contra o terrorismo, ocorreu uma das maiores escaladas da guerra não só contra as organizações guerrilheiras, mas contra todas as expressões de organização e mobilização social e política de esquerda, de oposição, ou de reivindicação de direitos humanos, sociais, políticos, etc.

6 Tentativa que surge no marco dos Encontros Nacionais de Estudantes de Trabalho Social (ENETS) desde finais da década de 1990 e início da década de 2000, que vai se estender até 2007, mas que não se consolida. Já em 2004 estudantes da Universidade Nacional da Colômbia protagonistas na construção dessa proposta decidem abortá-la, e em plenária do ENETS ficou decidido não continuar essa construção. Mas em 2005 novamente o debate entra em pauta, o que leva à decisão de avançar nessa construção fora do espaço ENETS e dos consultivos (espaço preparatório dos mesmos). Assim entre 2006 e 2007 se realizam reuniões preparatórias da OCETS, avançando numa proposta formal de organização, sem levar em conta os acúmulos anteriores. Finalmente em 2008 esta dinâmica fica completamente interrompida. Está pendente uma análise sobre esse processo, seus avanços, limites e contradições, especialmente pensando na necessidade da organização estudantil.

7 Participaram como convidados desse I Encontro: Carlos Montaño pelo Brasil, César Barrantes pela Venezuela, Gloria Cuartas pela Colômbia, Marcos Chinchilla pela Costa Rica e Natalio Kisnerman pela Argentina.

8 O Coletivo da Univalle se soma ao processo de organização na reta final em 2008, participando na revisão e aprovação dos trabalhos inscritos e colaborando na logística do evento. Será também no marco do I Congresso que será conhecido o processo que estava sendo realizado em Caldas, e a partir daí sua aproximação e articulação com o processo nacional.
9 Além da participação novamente de Gloria Cuartas pela Colômbia. Cuartas é formada em Trabalho Social, mas tem se destacado como defensora de direitos humanos e lutadora social e política. Foi prefeita de ApartadóAntioquia, um município fortemente atingido pelo exército nacional e pelo paramilitarismo (principalmente quando, não por acaso, Uribe Vélez era Governador de Antioquia), onde existe uma importante experiência de Comunidade de Paz, em uma tentativa de neutralizar a ação de todos os atores armados sobre a população.

10 Tema central desse I Congresso.

11 Está pendente uma análise mais coletiva sobre as dificuldades (e suas causas) que têm sido apresentadas para a continuidade nesses e em outros processos.

12 Desde o ano 2009 tem havido uma marcada participação internacional, principalmente na presenca como Coletivo no XIX Seminário Latino-americano de Escolas de Trabalho Social e na Assembleia da Asociación Latinoamericana de Enseñanza e Investigación en Trabajo Social (ALAEITS) (experiência que se repetiu em 2012), e a partir daí com participação em eventos em diversos países, em muitos das quais foram como convidados e em outros apresentando trabalhos.

13 Alguns dos trabalhos de membros do Coletivo apresentados no terceiro Congresso Latino-americano de Trabalho Social Crítico que possibilitam uma aproximação com esta reflexão são os de Andrés Contreras (2014), Diana Ramirez Duarte (2014), e Sergio Quintero Londoño (2014).

14 Carlos Montaño (uruguaio) e Ramiro Dulcich Piccolo (argentino) fizeram seus estudos de pós-graduação no Brasil e atualmente são, respectivamente professores efetivos nas universidades Federal de Rio de Janeiro e na Federal Fluminense. Ainda que ambos sejam marxistas, propuseram análises diferenciadas. Pela Colômbia foram convidados: Gloria Cuartas, Miguel Ángel Beltrán (professor universitário que foi preso político durante dois anos, criminalizado por sua produção intelectual sob sofismas de uma suposta vinculação com a insurgência armada das FARC-EP. Depois, quando em liberdade foi destituído de seu cargo como professor da Universidade Nacional de Colômbia. Posteriormente, foi novamente preso sob o argumento de seu suposto vínculo com as FARC-EP); Roberth Salamanca (um dos fundadores do processo de Trabalho Social Crítico da Colômbia em 2004, atualmente é professor e diretor da Escola de Serviço Social na Universidade privada Externado de Bogotá) e Sergio Quintero (membro de Trabalho Social Crítico desde 2007, inicialmente em Caldas e atualmente no Rio de Janeiro).

15 Esse foi também o congresso com uma participação mais qualificada em termos dos trabalhos de estudantes, professores e profissionais, inclusive não só do Trabalho Social e não só da Colômbia.

16 Já em outros trabalhos temos também tentado contribuir nesse sentido. Uma síntese pode ser encontrada no artigo: A vigência da luta de classes e a construção de um Serviço Social Crítico na América Latina, em avaliação na Revista Praia Vermelha vol. 24 No. 2. Também encontramos elementos na dissertação de mestrado de Salamanca (2010). Entre outras produções de membros do Coletivo. 
17 Entendemos aqui que o processo de paz é um só, mesmo que se tenham diversas mesas de diálogo entre o Governo e as insurgências armadas. Com as FARCEP começou o diálogo formal e público a partir do segundo semestre de 2012; com o ELN ainda está em andamento o processo exploratório prévio ao diálogo formal e público, espera-se que ainda no início de 2016 a abertura desse diálogo seja efetiva; com o EPL que se saiba não há aproximações, mas essa organização já expressou seu interesse em entrar em um processo de diálogo.

18 Texto chave para uma aproximação diversa sobre a guerra na Colômbia. É o texto da Comissão Histórica do Conflito e suas Vítimas (CHCV) (2015), surgido do processo de diálogo em Havana, onde intelectuais de diversas perspectivas teórico-políticas apresentam suas teses sobre o denominado conflito armado e contribuem para pensar encaminhamentos no processo da paz. Este documento por sua vez será a base da comissão histórica da verdade acordada entre as partes em Havana.

19 Sendo necessário refletir sobre outras propostas como a conformação de novas entidades, por exemplo, sindicais (no último 3 Congresso Latino-americano de Trabalho Social Crítico esta foi uma proposta apresentada de maneira introdutória por Alexandra Torres Romero e Ricardo Plazas Neisa (2014)).

\section{Juan Pablo Sierra Tapiro}

Assistente Social

Doutor em Serviço Social na Universidade Federal do Rio de Janeiro (UFRJ)

Membro do Coletivo Trabajo Social Crítico de Colombia e Professor do Curso de Serviço Social na Universidade Federal da Integração Latino-Americana (UNILA)

E-mail: juantapiro@gmail.com

\section{Universidade Federal da Integração Latino-Americana} - UNILA

Tancredo Neves Avenue, 6731 - Block 4

Foz do Iguaçu/ Paraná

CEP: 85867-970 